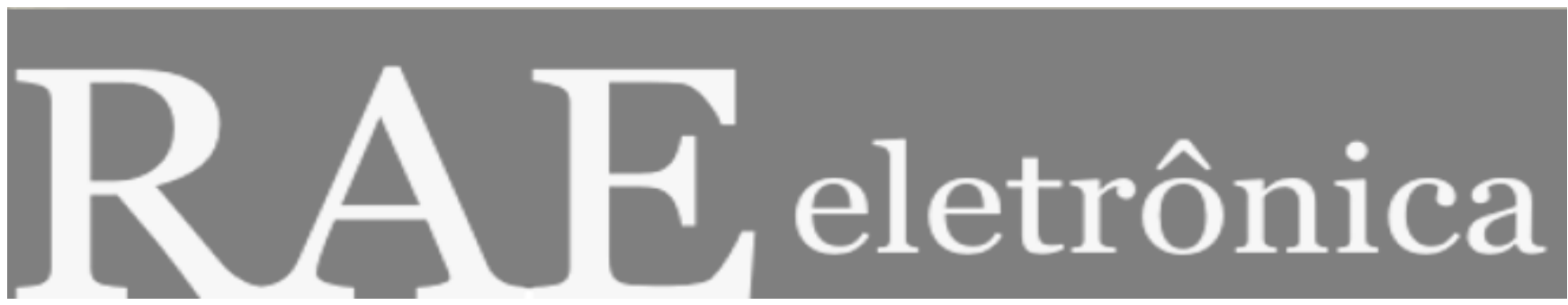

COMO CONSTRUIR MARCAS LÍDERES / BRAND ASSET MANAGEMET / BUILD YOUR OWN GARAGE

Por

José Mauro da Costa Hernandez

RAE-eletrônica, Volume 1, Número 1, jan-jun/2002.

http://www.rae.com.br/eletronica/index.cfm?FuseAction=Artigo $\&$ ID $=1367 \&$ Secao=RESENHAS\&Volume $=1 \& N u m e r o=1$ $\& A n o=2002$

CCopyright, 2002, RAE-eletrônica. Todos os direitos, inclusive de tradução, são reservados. É permitido citar parte de artigos sem autorização prévia desde que seja identificada a fonte. A reprodução total de artigos é proibida. Os artigos só devem ser usados para uso pessoal e nãocomercial. Em caso de dúvidas, consulte a redação: redacao@rae.com.br.

A RAE-eletrônica é a revista on-line da FGV-EAESP, totalmente aberta e criada com o objetivo de agilizar a veiculação de trabalhos inéditos. Lançada em janeiro de 2002, com perfil acadêmico, é dedicada a professores, pesquisadores e estudantes. Para mais informações consulte o site www.rae.com.br/eletronica.

RAE-eletrônica

ISSN 1676-5648

(C)2002 Editora: Fundação Getulio Vargas - Escola de Administração de Empresas de São Paulo.

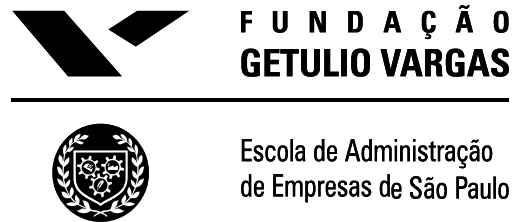




\section{COMO CONSTRUIR MARCAS LÍDERES / BRAND ASSET MANAGEMET / BUILD YOUR OWN GARAGE}

Por José Mauro da Costa Hernandez,

Bacharel e mestre em administração de empresas pela FEA-USP e doutorando em administração de empresas na FGV-EAESP.

E-mail:jimhernandez@fgvsp.br

\section{Como Construir Marcas Líderes}

De David A. Aaker e Erich Joachimsthaler

Ed. Futura, 2000

Brand Asset Management Driving Profitable Growth Through Your Brands

De Scott M. Davis,

Ed. Jossey-Bass, 2000

\section{Build Your Own Garage}

De Bernd H. Schmitt e Laura Brown

The Free Press, 2001-11-15

Embora as marcas venham despertando a atenção de acadêmicos e profissionais de marketing há muito tempo, foi só apenas no final dos anos $80 \mathrm{com}$ a criação do conceito de brand equity ${ }^{1}$ que o interesse pelo estudo das marcas ganhou um verdadeiro impulso. Desde então, mas particularmente nos últimos anos, um grande número de livros sobre o assunto tem sido publicado. Poucos, entretanto, conseguem se destacar por contribuir com idéias e conceitos novos ou com práticas gerenciais mais eficazes para a criação e manutenção de marcas fortes. Os livros revistos aqui não são uma exceção.

Como Construir Marcas Lideres, por David Aaker e Erich Joachimsthaler (a partir daqui, A\&J), é o terceiro livro da trilogia sobre criação e gerenciamento de marcas, iniciada com Marcas - Brand Equity (Ed. Negócio, 1998) e seguida por Criando e Administrando Marcas de Sucesso (Ed. Futura, 1996). Embora a leitura dos livros anteriores não seja pré-requisito para Como Construir Marcas Líderes, o leitor pouco familiarizado com alguns dos conceitos expostos nos livros anteriores, principalmente os conceitos de brand equity e identidade de marca, pode deixar de apreciar totalmente este novo livro.

Segundo A\&J, o modelo Procter \& Gamble de gerenciamento de marcas não é mais viável num ambiente cada vez mais complexo e competitivo e sugerem que este modelo deve ser substituído por um novo paradigma, batizado por eles "brand leadership" (título original do livro). Neste novo paradigma: 1. o gerenciamento da marca deixa de ser tático para ser estratégico e deve ser liderado pelos níveis mais altos da organização; 2 o foco do gerenciamento da marca deixa de ser limitado e local para se tornar amplo e global, enfatizando múltiplos produtos, mercados e países; 3 . a estratégia deixa de ser dirigido pelos resultados de vendas e participação de mercado para ser dirigido pela identidade de marca.

$\mathrm{Na}$ primeira parte do livro, A\&J explicam brevemente este novo paradigma e salientam a importância das marcas. No restante do livro, A\&J exploram quatro temas que segundo eles seriam as 
bases deste novo paradigma. Para quem leu Criando e Administrando Marcas de Sucesso, o primeiro tema, identidade de marca, não é exatamente novidade.

O segundo tema explorado no livro trata da arquitetura de marcas, ou seja, como as marcas de uma organização devem relacionar-se entre si, quanto cada marca pode ser estendida a outras categorias de produtos e qual o papel de cada marca dentro do sistema de marcas da organização. Embora David Aaker tenha tratado deste assunto em seus dois livros anteriores, neste livro A\&J conseguiram organizar de maneira bastante didática quais os diferentes papéis que uma marca pode assumir. Os autores também retomam a discussão sobre quanto uma marca deve ou não ser estendida e ensinam como elaborar uma auditoria de arquitetura de marcas.

O terceiro tema trata sobre a construção de marcas além da utilização da propaganda tradicional. O objetivo desta parte do livro é mostrar que, embora a propaganda seja instrumento extremamente importante na criação e manutenção de uma marca, isto não quer dizer que ela seja necessária ou suficiente e muito menos que a tarefa de se criar e manter uma marca deva ser delegada às agências de propaganda.

O primeiro capítulo desta terceira parte foi completamente dedicado à história da disputa pelo mercado americano de calçados e roupas esportivas por Adidas e Nike. No entanto, a melhor parte está no sumário das lições que podem ser aprendidas com esta história. Entre outras, os autores ensinam: 1. Criar uma marca não é apenas fazer propaganda; 2. Criar uma marca depende de inovação; 3 . Os produtos são o principal elemento de uma marca; 4. Uma marca é mais que seus produtos.

No segundo capítulo desta parte, A\&J mostram como a marca Mastercard, através do patrocínio da Copa do Mundo de Futebol, obteve sucesso tanto aumentando o reconhecimento da sua marca quanto melhorando as atitudes dos consumidores em relação à marca. $\mathrm{O}$ capítulo dá algumas dicas de como utilizar eficientemente o patrocínios na construção de marcas (por exemplo, "mobilize toda a organização em torno do patrocínio", "proporcione uma experiência aos seus consumidores através do patrocínio" ou "explore ao máximo as possibilidades de exposição da marca") e como evitar as ameaças de um patrocínio que não deu certo.

Gostaria de destacar, entretanto, o terceiro capítulo desta parte que trata sobre o papel da Internet na criação de marcas. Através de exemplos atuais e muito interessantes, os autores mostram que a Internet pode e deve ser utilizada de forma criativa no apoio às marcas. No entanto, deve-se evitar a utilização da Internet como uma mídia convencional; o segredo é explorar as características únicas da Internet, como a interatividade, para se criar experiências. $\mathrm{O}$ último capítulo desta parte retoma diversos exemplos para demonstrar que é possível criar marcas sem o uso excessivo de propaganda e dá algumas diretrizes de como isto deve ser feito.

Finalmente, o quarto tema trata dos dilemas na criação de marcas globais. Este assunto se torna extremamente relevante na medida em que cada vez mais se discute os efeitos da globalização sobre os consumidores e muitas empresas têm se voltado para o alinhamento de suas agências de propaganda como forma de garantir a uniformização de sua comunicação. Segundo A\&J, a prioridade não deve ser a de desenvolver marcas globais (embora isto possa acabar ocorrendo), mas sim o desenvolvimento de marcas globais líderes, isto é, marcas fortes em todos os mercados, suportadas por um gerenciamento global eficiente e pró-ativo.

Bernd Schmitt, ou como ele prefere ser chamado, SCHMITT, um dos autores de Build Your Own Garage, já é conhecido do público brasileiro por seus outros dois livros: A Estética do Marketing 
(Livraria Nobel, 1998), escrito em parceria com Alexander Simonson e Marketing Experimental (Livraria Nobel, 2001). Build Your Own Garage não é exatamente um livro sobre gerenciamento de marcas. No entanto, SCHMITT tem se dedicado intensamente ao estudo de marcas (ele é um dos diretores executivos do Centro para a Liderança de Marcas Globais da Escola de Negócios da Universidade de Colúmbia, Nova Iorque) e Building Your Own Garage está impregnado de suas idéias sobre como as marcas devem ser gerenciadas. O livro também trata sobre um tema extremamente relevante para o aperfeiçoamento do gerenciamento de marcas: criatividade.

E já que o tema principal do livro é criatividade, o livro também vale pelo esforço de SCHMITT e Laura Brown em trazer ao leitor um livro num formato bastante criativo. A começar pelo título, uma alusão às empresas que começam em garagens (embora esta metáfora esteja muito mais próxima da realidade americana que da realidade brasileira), caracterizadas entre outras coisas, pela paixão, criatividade, inovação, rapidez e flexibilidade que seus empreendedores conseguem imprimir a este tipo de organização. SCHMITT prega que as grandes corporações devem tentar adotar o espírito que existe nestas corporações de garagem.

Mas o livro também é inovador por diversas outras razões. Por exemplo, cada capítulo inicia-se com uma fábula ilustrando aspectos negativos das organizações burocráticas, estruturadas, quadradas e vagarosas. As fábulas, além de ilustrarem princípios importantes, são destinadas tanto ao aprendizado quanto ao prazer da leitura (e aqui entra Laura Brown). Assim, diferentes personagens nos são apresentados: o vampiro, representado pelo executivo Dean Calendula e que se dedica a sugar a vida de seus empregados; o executivo aborrecido por tantas viagens de avião mas acaba se deslumbrando com a experiência proporcionada pela companhia aérea; e a eficiente e brilhante executiva de marketing que se apaixona pelo tímido consultor de marcas. Cada história é contada em um gênero diferente (história de vampiros, história de amor, história de detetives, história infantil) e ambientada em diferentes situações (a organização de garagem adquirida pelo conglomerado corporativo, a empresa que perdeu sua identidade após uma série de fusões ou a empresa que está encontrando dificuldades em se relacionar com seus clientes).

O livro também é intensamente ilustrado com fotografias, desenhos, gráficos e pequenas histórias, tornando o livro, segundo seus autores, uma obra de experiência multi-mídia. Até criaram um Website (www.buildyourowngarage.com) onde alguns dos conceitos discutidos no livro são ilustrados (sim, inclui um vídeo da história de amor). Mas o livro não é interessante apenas por discutir criatividade de uma forma criativa (pelo menos para livros de negócios). De certa forma, este livro está bastante relacionado ao seu livro anterior, Marketing Experimental, em que SCHMITT sugere que as organizações devem estar voltadas para a criação de experiências. Neste livro SCHMITT sugere que além de criar experiências, as organizações devem ser criativas e para tanto, devem alinhar o bizz, o buzz e o stuff. Bizz, segundo ele, corresponde ao conjunto de atividades estruturadas e bem organizadas que resultam do espírito Apoloniano da organização (a organização Apoloniana tem uma natureza racional: harmoniosa, ordenada e planejada); buzz corresponde à motivação, paixão e excitação, resultantes do espírito Dionisiano da organização (a organização Dionisiana é criativa e passional); finalmente, stuff corresponde à estrutura física da organização, aos processos, à tecnologia e ao onhecimento que permitem à organização operar eficientemente.

No entanto, o núcleo do livro consiste em três capítulos em que são discutidos os "mestres da arte" da garagem: tecnologia, gerenciamento de marcas e gerenciamento de experiências dos clientes (note que não é o mesmo que gerenciamento de relacionamento com clientes!). Os "mestres da arte", segundo SCHMITT, seriam os principais responsáveis por trazer o espírito criativo das empresas de garagem de volta às grandes corporações. 
O capítulo que despertará mais interesse aos interessados em marcas é o que fala sobre o "mestre da arte" gerenciamento de marcas. Neste capítulo SCHMITT tenta mostrar que o gerenciamento de marcas no estilo tradicional e conservador (o estilo Procter\&Gamble, mencionado por Aaker), em que o "departamento de marketing" é o dono da marca e gerenciar marcas é gerenciar os 4 P's, não encontra mais lugar nos dias de hoje. Num ambiente em que tudo passou a ser uma marca e o mercado está abarrotado de ofertas, o gerenciamento da marca tem que ser feito por todas as pessoas da empresa. Para tanto, os empregados têm que estar conscientes do significado da marca e o que ela deve representar para os seus clientes para que suas ações reflitam a verdade sobre a empresa e seus produtos.

Bom gerenciamento de marcas, prega SCHMITT, consiste em diferenciar de forma significativa a organização dos seus concorrentes, desenvolver os produtos e serviços que os consumidores desejam e atuar estrategicamente. A marca deve direcionar e unificar as forças da organização de forma que todas as pessoas utilizem a marca para guiar as suas decisões. Para tanto, continua ele, é necessário que as pessoas da organização "vivam" a marca e guiem seu comportamento em função dela. Se a organização não puder cumprir as promessas de suas marcas, a organização estará fadada ao fracasso.

Embora estes dois livros sejam uma continuação das obras anteriores de seus autores e retomem alguns dos conceitos já expostos anteriormente, é inegável que eles conseguem agregar conhecimento, além de serem muito ricos em exemplos de empresas que tiveram sucesso em administrar as suas marcas. O mesmo não se pode dizer de Brand Asset Management de Scott M. Davis. Para quem nunca leu nada sobre marcas, o livro pode ser de algum proveito; no entanto, os leitores que já leram pelo menos um bom livro sobre marcas não conseguirão tirar proveito da leitura deste.

Segundo Scott Davis, uma marca é um ativo e, assim, as marcas têm que ser gerenciadas como se fossem um ativo. E gerenciar uma marca como se fosse um ativo requer uma abordagem equilibrada de investimento destinada a criar um significado para a marca, comunicar este significado tanto interna quanto externamente e alavancar este significado de forma a aumentar a rentabilidade, valor e retorno da marca. Até aqui, Scott Davis não traz nada de novo já que este é exatamente o conceito de brand equity, criado no final dos anos 80 e bastante discutido em todos os anos 90 .

Após ter lido o primeiro capítulo, eu esperava que o autor fosse propor idéias novas sobre como gerenciar uma marca e aumentar o seu valor. Infelizmente, a metodologia de Scott Davis não traz nada de novo.

Além de pouco contribuir para a literatura sobre marcas, o livro também tem sérias falhas. Por exemplo, em várias ocasiões o autor se refere às suas aulas para executivos e alunos de MBA para ilustrar um conceito ou introduzir um exemplo. Além de não ter nenhum valor científico, este tipo de referência também não deve agradar o público gerencial, mais interessado em experiências reais com organizações reais. A segunda falha é que o autor faz diversas referências em todo o livro e nunca menciona as fontes, o que pode levar o leitor mais atento a chegar a duvidar das informações que o autor proporciona. Em algumas passagens, o autor dá diversos exemplos sem deixar muito claro como os exemplos se relacionam com os conceitos; em outras passagens, o autor simplesmente não incluiu nenhum exemplo. Enfim, o livro pode ser um bom início para leitores novatos no assunto, mas pode passar em branco para leitores mais experientes.

Os três livros expressam algumas mensagens que tem se tornado uma constante na literatura sobre marcas: a primeira mensagem é que a marca é um ativo muito importante de qualquer companhia para ser gerenciada apenas através de ações de curto prazo ou cuja administração possa ser relegada às 
agências de propaganda; a segunda mensagem é que se torna cada vez mais importante que os altos escalões da organização se envolvam mais diretamente com o futuro das suas marcas; a terceira mensagem é que as empresas devem se preocupar mais em proporcionar experiências memoráveis aos seus clientes e gerenciamento de relacionamento com clientes é apenas uma das formas de se fazer isto; por fim, as organizações devem se tornar mais criativas e buscar alternativas além da propaganda para criar e nutrir suas marcas.

${ }^{1}$ Apesar da expressão "brand equity" ter sido traduzida anteriormente para o português como "eqüidade de marca", prefiro usar aqui a expressão original por acreditar que a palavra eqüidade em português não tem exatamente o mesmo sentido que os teóricos americanos pretendem dar ao termo equity. 